\title{
Luchas y retos de la izquierda en el Líbano
}

\author{
The struggle and challenges of the Lebanese Left
}

Sultan Salim Hamade*

\begin{abstract}
Resumen: El Líbano nunca fue un país ajeno a la lucha de los movimientos populares y de la izquierda internacional. Históricamente fue un terreno fértil para la implementación de políticas de participación popular en un ambiente profundamente ecuménico en lo étno-cultural, multiconfesional y nacional. Sin embargo, el sistema neoliberal implementado por la elite burguesa antinacional desde el fin de la guerra civil en 1991, ha marginado a los obreros, a los campesinos y a la clase media y desde el poder, han tratado de eliminar a dichos movimientos para conservar e incrementar el sistema de prebendas y privilegios que usufructúan y su hegemonía socio-económica. Este artículo, desde un enfoque marxista-leninista y tercermundista, hace un análisis de dicha situación y de los desafíos a los que se enfrentan los movimientos de izquierda en el Líbano; además, en él se abordan las tácticas agresivas de la burguesía en contra de las clases trabajadoras del país.
\end{abstract}

Palabras clave: Líbano, izquierda, neoliberalismo, capitalismo, partido comunista del Líbano, trabajadores, elites

Abstract: Lebanon was never distant from the rise and struggle of international leftist and popular movements. Historically its political arena was fertile for the rise of popular movements and vertical alliances as an alternative to confessional and ethnic coalitions. In addition the neoliberal policies implemented by the bourgeoisie elites after the 1975-1991 civil war, fortified the marginalization of workers, peasants and middle classes. The elites in power aimed to destroy the popular revolutionary movements in order to preserve their own hegemonic socio-economic system of privileges. This paper provides a Marxist-Leninist analysis for the challenges facing Leftist movements in Lebanon; moreover, it studies the bourgeoisies' tactics of aggression against the working class.

Keywords: Lebanon, Left, neoliberalism, capitalism, Lebanese communist party, workers, elites

Recibido: 30 mayo 2018 Aceptado: 30 julio 2018

\footnotetext{
${ }^{*}$ M. Sc. Sultan Salim Hamade, Ciudadano libanés y ucraniano, Doctorando en Ciencias Políticas por la Facultad de Filosofía e Historia, Departamento de Filosofía y Teoría Política para las Ciencias Sociales y Económicas de la Universidad de la Habana, Cuba. Correo: sultanhamadi@nauta.cu.
} 


\section{Introducción}

Los últimos eventos del siglo XXI, y la crisis económica que desde el 2008 afecta al planeta, han demostrado que el sistema capitalista mundial no es sostenible y mucho menos es viable el orden neoliberal que le han insuflado los neoconservadores. A lo anterior se puede agregar, el estallido incontrolable de guerras imperialistas, la ampliación injustificada de la OTAN y el innecesario crecimiento vertiginoso de los presupuestos militares en el mundo, el destrozo del medio ambiente y el crecimiento vertiginoso de la brecha socio-económica entre los más ricos y los más pobres, eventos que en su conjunto demostraron las fallas de la teoría del fin de la Historia ${ }^{1}$ y de la victoria del capitalismo y revitalizan los presupuestos fundamentales de la doctrina marxista-leninista, principalmente su método dialéctico materialista.

Por otra parte, y en repuesta a la avalancha neoliberal globalizada, las masas de desposeídos, el "pobretariado" 2 a decir del Dr. Villar Barroso, se movilizaron en varios países y se organizaron para combatir el orden neoliberal impuesto y tratar de revertir sus efectos catastróficos. El Líbano no está al margen de estas dinámicas y también en el país se ha producido cierto avance de la lucha de los movimientos de las izquierdas populares.

En este trabajo abordamos algunos momentos de este enfrentamiento en el escenario libanés y exponemos nuestras ideas sobre sus potencialidades y limitaciones, que son, en efecto, quienes mejor explican porque los resultados de la lucha popular no han conseguido avanzar en el desmontaje de un sistema ajeno a la realidad de nuestro país y por extensión, autodestructivo. Con ello pretendemos explicar cuestiones claves que han lacerado los esfuerzos del pueblo libanés y las limitaciones ideológicas de sus dirigentes populares.

La lucha del pueblo libanés no ha sido fácil, ya que, concluida la guerra civil en 1991, las elites burguesas del país impusieron un programa neoliberal basado en la implementación de un modelo económico sustentado en la economía de servicios y el desarrollo del turismo, es decir, un modelo que relegaba al sector productivo. En su lugar, abría los mercados nacionales, sin ningún tipo de regulación, a las mercaderías foráneas en detrimento de las propias y en consecuencia, se ha producido una marginalización de los trabajadores industriales, de los campesinos y de otros sectores de la clase media.

Los oprimidos del país lucharon desde sus partidos de izquierda y los sindicatos, para tratar de mejorar su situación y lograr la justicia social necesaria. No obstante, sus esfuerzos han chocado las medidas adoptadas por la derecha nacional, aupada por las transnacionales y apoyada por los neoconservadores árabes y occidentales, lo que les ha permitido contar con las herramientas necesarias para combatir dichos movimientos y preservar su posición privilegiada.

Después la caída de la URSS y el fin de la guerra civil en el país, las uniones de los trabajadores quedaron paralizadas, y el Partido Comunista del Líbano sufrió una fuerte crisis doctrinal y estructural. ¿Cuáles serían los retos de la izquierda en el Líbano en su lucha para la justicia social? En este artículo tratamos primero de un análisis del mito burgués libanes con

\footnotetext{
${ }^{1}$ Francis Fukuyama, El fin de la historia y el último hombre. Editorial Planeta. 1992. ISBN 978-84-320-5954-4.

2 Término usado sistemáticamente en sus conferencias por el Dr. C., y Profesor Titular de Ciencias Políticas de la Universidad de La Habana, Oscar Julián Villar Barroso, para designar a la masa creciente de desposeídos, que han quedado al margen y relegados por las políticas aplicadas por el capitalismo neoliberal y globalizado. Se puede ampliar en su artículo: "Los fulgores de Octubre en las estepas centroasiáticas". Revista UH no.284. La Habana. jul.dic. 2017. ISSN: 0253-9276.
} 
un enfoque materialista revolucionario, luego del neoliberalismo de la posguerra civil y al final, del resurgir en el país de los movimientos populares y de la clase obrera.

\section{La realidad revolucionaria contra el mito burgués}

No resulta ocioso señalar, aunque es una verdad de Perogrullo, que cualquier corriente ideológica trata de suprimir a sus adversarios para preservar sus posiciones dentro de cualquier sistema. En el lenguaje académico de la clase burguesa del Líbano, existe un mito acerca de que no hay lucha de clases en el país, que en la sociedad libanesa solo predominan las divisiones sectarias y confesionales y que los individuos, solo tienen espacios de participación dentro sus clanes o en las entidades con etiqueta religiosa ${ }^{3}$.

El Estado burgués libanés promueve dicho mito en sus instituciones educativas y medios de comunicación para defender sus privilegios, sus negocios privados y las relaciones carnales que ha construido con el imperialismo internacional. Además, la constitución del país, en su Artículo № 6, indica claramente que la economía del país es liberal y reconoce y tutela la propiedad privada 4 .

En su pensamiento, el Líbano era algo así como la Suiza del Medio Oriente, un país donde los 18 grupos religiosos coexistían pacíficamente porque el sistema político consociacionalista ${ }^{5}$ mantenía el balance y la cooperación entre todos los grupos étnicos y sectarios, y era el garante de la estabilidad nacional. En fin, que para ellos el Líbano era el paraíso terrenal, el mejor lugar para hacer turismo y donde la pobreza no existía.

En tanto, aseguran que todo cambió cuando al país comenzaron a llegar los refugiados palestinos, cuyo flujo dispuso una carga adicional para la frágil sociedad sectaria del Líbano ${ }^{6}$. Además, en opinión de los personeros de esta burguesía, esos refugiados palestinos cambiaron el equilibrio sectario y religioso libanés, destruyeron la coexistencia pacífica de los grupos religiosos y trajeron la pobreza al país porque no aspiraban a trabajar ${ }^{7}$. De la tal manera, esta misma derecha nunca reconoció que la guerra civil que vivió el país tenía un motivo clasista, ya que como clase tiene un objetivo muy claro: esconder la realidad de su opresión clasista y las contradicciones internas del sistema que han impuesto al país.

Claro que esto no hubiese sido posible de no haber contado desde antes del "boom" neoliberal con el apoyo del imperialismo internacional, al cual ha estado supeditado y en cuya dependencia económica ${ }^{8}$ se encuentra el origen de la crisis sistemática que ha vivido el país. A inicios del año 1966, el Líbano entró en una crisis socio-económica muy seria, que se agudizó, a tenor con las estadísticas de la época, en la dependencia del país al capital foráneo, así encontramos que los bancos extranjeros poseían el 93\% de los créditos bancarios, o que solo durante el año 1968, se registraron 499 compañías comerciales estadounidenses sin ningún tipo de control o restricciones de parte del Estado burgués.

\footnotetext{
3 Mahdi Amel, In the Secterian State, Beirut, Dar Al Farabi, 1986, 39.

${ }^{4}$ Fawaz Traboulsi, Michel Chiha and the Lebanese Ideology, Beirut, Riad Al Rayes Books, 1999, 38.

5 Gobierno de las elites que representan varios grupos religiosos.

6 Sultan Hamade, Líbano: ¿Crisis de las Comunidades Confesionales o Crisis del Sistema Burgués?, Marxismo y Revolución No.2 Febrero, 2018, 6.

7 Mahdi Amel, Introductions to Critic the Sectarian thought, Beirut, Dar Al Farabi, 1989, 265.

8 Reinaldo Sánchez Porro, El Líbano Crisis y Comunidades Confesionales (1840-1943), La Habana , Editorial Félix Varela, 2001, 105
} 
Como resultado de lo anterior, las compañías extranjeras comenzaron a ejercer una dominación creciente sobre la industria nacional libanesa, y se impuso una relación monopólica ${ }^{9}$ de entidades foráneas sobre las industrias médico-farmacéutica, el plástico, el azúcar, el tabaco, la leche y el algodón. El Estado, con su matriz capitalista, rechazó proteger a las compañías nacionales frente a la inyección del gran capital de las compañías multinacionales. Además, el gobierno estadounidense, obligó al banco central a comprar el dólar a un precio muy alto ${ }^{10}$. Por supuesto, el resultado fue catastrófico y resultó en una inflación descontrolada.

Igualmente, la penetración acelerada del capitalismo transnacional en el sector de la agricultura, destruyó la pequeña propiedad campesina nacional. Los campesinos pobres no podían pagar por el transporte de sus productos, ni comprar los caros paquetes tecnológicos para mantener adecuados niveles de producción, resultando imposible la competencia con las grandes empresas de exportación de frutas y vegetales. Por ello, los campesinos tenían dos opciones:

1) Dejar o vender sus tierras y trabajar por un salario miserable en las grandes empresas agrícolas.

2) Dejar o vender sus tierras y mudarse para la ciudad para trabajar en fábricas o en el sector del turismo y de los servicios ${ }^{11}$.

Así, los campesinos que migraron para las ciudades formaron con los trabajadores de las fábricas y los trabajadores del sector del turismo la clase proletaria del Líbano. En el año 1970 el gobierno comunicó a la población, que la cantidad máxima de trabajadores a emplear en el sector público había llegado a su límite y desde entonces aumentó exponencialmente la tasa de desempleo, que llego a ser de hasta el 10\% de la población laboralmente activa.

En consecuencia, los años 1971-1973 fueron testigos de varias marchas y huelgas de trabajadores, campesinos, estudiantes e intelectuales. Los activistas y militantes demandaron servicios sociales, salud pública y la limitación a la actividad de los monopolios. Así, la crisis de los campesinos y la tierra, dio inicio a una rebelión masiva contra las compañías extranjeras.

El movimiento campesino no solo exigió mejores salarios y precios para sus productos, además, pidieron la nacionalización de la tierra de las instituciones religiosas y de las élites que trabajaban en la política, insuflándole una cualidad superior a su lucha clasista. Y ante la actitud pasiva ante sus demandas de parte de las autoridades, en la provincia de "Akkar", un grupo campesino inició un movimiento armado, que fue apoyado por los partidos de izquierda. Los granjeros de la compañía de "Regi", responsable de la producción y exportación de tabaco, comenzaron una rebelión para mejorar sus situaciones y hasta llegaron a pedir la nacionalización de la compañía.

En el año 1973 los trabajadores de la misma compañía tabacalera ocuparon las oficinas de esta en el sur del país. El Estado respondió mediante el empleo de la fuerza y los militares mataron a varios trabajadores ${ }^{12}$. En respuesta, el mismo día unos 20 mil trabajadores y

${ }^{9}$ Sulieman Takieldeen, The Historical Development of the Lebanese Crisis 1920-1970, Beirut, Dar Ibn Khaldoun, 1977, 121.

10 Takieldeen, op. cit., 23.

11 Fawaz Traboulsi, A History of Modern Lebanon From the Imarah to the Taef Accords, Beirut, Riyad Al Rayes Books, 2008, 283-285.

12 Traboulsi, op. cit.,294-297. 
estudiantes ocuparon las calles de Beirut en solidaridad con el movimiento revolucionario de los campesinos, fue denunciado el gobierno burgués por el crimen cometido en la defensa de los intereses del capital privado y el Estado suspendió el derecho de manifestación. Los trabajadores respondieron con más marchas $y$ con ataques contra las oficinas gubernamentales ${ }^{13}$.

En medio de esta situación, el 21 de enero de 1973, los trabajadores de la fábrica "Ghandour ${ }^{14 "}$ iniciaron una rebelión obrera en contra de la patronal que concluyó en una masacre cuando la policía ocupó la instalación fabril. De tal manera, el Estado burgués enfrentó las demandas obreras por medio de la fuerza y la violencia. Además, inició una campaña de propaganda en la que asociaba a dichos movimientos al objetivo de conducir al Líbano al "Conflicto Árabe-Israelí", en pleno auge por entonces, aprovechando de que muchos obreros del país simpatizaban con el programa y la ideología revolucionaria del "Movimiento Nacional", que luchaba para un cambio estructural en la sociedad libanesa y la justicia, y que tenía un alto componente de solidaridad con la causa árabe y de rechazo al sionismo. La movilización armada de los obreros libaneses comenzó a incrementarse y pudieron contar con la ayuda de los guerrilleros palestinos refugiados en el Líbano.

Sin embargo, la situación se hizo muy complicada para la causa libanesa, sobre todo cuando los partidarios del "movimiento nacional” afirmaron: “...que el momento histórico para un cambio revolucionario había llegado...", y proclamó su famoso programa que abogaba por un cambio estructural para terminar en el país con el modelo de la democracia consociacional, de carácter burgués, y con la secularización del Estado. Como respuesta, la derecha movilizó a sus acólitos, portadores de una ideología racista y xenófoba, contraria a la causa del pueblo palestino. Su ideología, de orientación religiosa, relacionaba el pensamiento revolucionario con el Islam, y de la peor manera. Además la derecha declaró que era necesario combatir el programa del "movimiento nacional" con las armas 15.

El 26 de febrero de 1975 los pescadores pobres de la cuidad de Saidon, iniciaron una marcha contra la concesión por parte del Estado a la compañía internacional de "Proton", del derecho a la explotación exclusiva de los recursos pesqueros en la plataforma libanesa. Durante la marcha, Marouf Saad, líder de los pescadores y miembro del "Movimiento Nacional", fue asesinado. Por supuesto, las facciones armadas de la izquierda y de derecha de Saidon iniciaron una batalla campal 16 .

Fue así como las contradicciones socio-económicas en el Líbano se hicieron más agudas, los enfrentamientos entre las distintas facciones políticas más cruentos y sistemáticos y la situación insostenible, en medio de esta situación, el 13 de abril de 1975 las acciones armadas estallaron en todo el país en un conflicto armado que se extendió hasta 1991. Una guerra civil que bien pronto se convirtió en un conflicto geopolítico con la participación de Israel, Siria y las guerrillas palestinas.

13 USADOS, Annual Labour report 1972-1973, Beirut, 1973, 25.

14 La fábrica más grande de su época.

15 Suleiman Takieldeen, El tema del sectarismo en el Líbano, sus raíces y desarrollo, Beirut, Dar Ibin Khaldoun, 1980, 40-412.

16 Fawaz Traboulsi, $A$ History of Modern Lebanon from the Imarah to the Taef Accords, Beirut, Riyad Al Rayes Books: $2008,323$. 


\section{El Líbano y el Neoliberalismo}

Al fin de la guerra civil en 1991, las élites que manejaron las milicias en la guerra modificaron el sistema de poder político en el país y su matriz económica. Siempre, según esas mismas élites, la causa fundamental del inicio de la guerra civil fue el cambio en el equilibrio del orden sectario al interior de la sociedad libanesa, en tanto, lo cierto es que en el estallido de la contienda tuvo un efecto indiscutible el rejuego geopolítico que por esos años trastocó el statu quo de la región, instigado por el imperialismo internacional que optó por convertir al sionismo en su punta de lanza en la región. Como un resulto final de la guerra, las élites redistribuyeron la cuota sectaria en el parlamento, en el gobierno, en el ejército y en las otras instituciones del Estado ${ }^{17}$.

Por el contrario, las elites nunca tocaron el tema de la desigualdad social que se había hecho presente antes de la guerra civil y que se agudizó muchísimo cuando comenzaron a implantar una estrategia neoliberal más agresiva y radical. En dicha época, varios cambios en el orden regional e internacional configuraron un contexto favorable que dejó la vía expedita para la implementación del neoliberalismo en el Líbano ${ }^{18}$.

El vergonzoso derrumbe de la Unión Soviética dejó desorientados al Partido Comunista del Líbano y al "Movimiento Nacional", quienes tampoco pudieron contar con el apoyo militar y financiero de Moscú. Comenzaron a prevalecer entonces, aunque temporalmente, las teorías del pensamiento capitalista como la del "fin de la historia" y el pensamiento neoliberal se impuso sobre todas las demás corrientes. El establecimiento de la colación internacional contra Iraq en 1990, dio luz verde al gobierno de Siria para tratar de terminar la guerra civil en el Líbano. La propagada imagen del carácter sectario de la guerra civil paralizo las fuerzas de izquierda, que en lo adelante no pudieron movilizar a los obreros en pos de un cambio revolucionario en el país ${ }^{19}$.

El nuevo presidente de Líbano, Elías El Herawi, propuso en 1992 a Rafiq Hariri para ocupar el puesto de Primer Ministro. Se trataba de un millonario que tenía una gran experiencia en el sector de la construcción, sobre todo en el golfo árabe, y muy buenas relaciones en Arabia saudita. Hariri tenía un plan para convertir el centro de la capital libanesa, Beirut, en un gigantesco emporio comercial y financiero, que seguía al pie de la letra los presupuestos del orden neoliberal que las instituciones financieras internacionales habían impuesto al país, sobre todo en cuanto a la matriz de la economía libanesa y la división del trabajo.

Así las cosas, el famoso plan de reconstrucción de Hariri, basado en la inversión en el sector del comercio, los servicios y el turismo, en lugar de invertir en la industria y la agricultura, fue concebido sobre la base de un importante endeudamiento público con la banca internacional, que significó para el pueblo libanés tener que arrastrar el lastre de una deuda de varios billones de dólares ${ }^{20}$ y muy poco provecho para la economía nacional.

Como apuntó Samir Amin: “...cuando el Estado burgués llega a un nivel maduro, el Estado siempre modifica su ideología de una manera más pragmática para preservar su sistema de

\footnotetext{
17 Samir Makdisi and Richard Sadaka, “The Lebanese Civil War, 1975-1991”, Lecture and Working Paper Series No.3 / American University of Beirut Institute of Financial Economics 2003, 37.

18 Elizabeth Picard, The Arab Uprisings and Social Rights: Asian Migrant Workers in Lebanon, Paris / Institut de Recherches et d'Études sur le Monde Arabe et Musulman Centre National de la Recherche Scientifique, 2014, 9.

19 Samir Makdisi and Richard Sadaka, The Lebanese Civil War, 1975-1991, Lecture and Working Paper Series No.3, American University of Beirut Institute of Financial Economics 2003, 32.

${ }^{20}$ Fawwaz Traboulsi, Social Classes and Political Power in Lebanon, Berlin Heinrich Böll Stiftung, 2014, 25.
} 
opresión..."21. Así mismo la clase burguesa analizó las tácticas de la clase obrera en la época antes de la guerra civil y descubrió la importancia de los sindicatos y de los partidos de izquierda para aglutinar a las clases trabajadoras y organizarlas para la lucha, a partir de comenzar por desmontar la propaganda racista y religiosa de la élite explotadora.

No es casual entonces, que, aprovechando el desconcierto de la izquierda en 1991, el Estado burgués libanés arremetiera contra los sindicatos y los partidos que representaban a los trabajadores para neutralizar su actividad. En ese escenario, las fuerzas de derecha se propusieron renovar sus tácticas pero a la vez cumplir con los elementos fundamentales de su ideología, orientándose a mantener el dominio político en una economía no productiva ${ }^{22}$.

Lo que estaba ocurriendo en esos tiempos en el país lo encontramos reflejados en los trabajos de uno de los principales del pensamiento burgués libanés, Michel Chiha ${ }^{23}$, quien aseguraba: “...el Líbano solo puede existir en el Medio Oriente como una isla de juegos de azar y turismo de lujo (...) la pobreza puede desalentar a los turistas, entonces es necesario mudar a los obreros lejos de nuestros polos turísticos...". Chiha justificaba su posición desde presupuestos abiertamente clasistas, más que sectarios o religiosos, y criticando los trabajadores de las fábricas decía: "...la industria no es parte de nuestra cultura ${ }^{24}$ (...) Al final del camino, los obreros industriales tienen solo dos opciones: desarrollarse como dueños de negocios o migrar a otros países para trabajar..." ${ }^{25}$, sus palabras ilustran con creces lo que hemos venido afirmando en este texto.

Si durante la guerra civil la clase burguesa hizo todo lo posible para por la fuerza obligar a los trabajadores a dejar la capital, e incluso, el país, desde el inicio de 1991 se plantearon una táctica neoliberal más suave, orientada a la destrucción de la base económica del país (industria y agricultura) y con mediante esto forzar la diáspora de mano de obra.

Un caso que ilustra el planteamiento anterior lo tenemos en la otrora célebre fábrica de "Ghandour, en fecha posterior a 1991 despidió a miles de trabajadores y ahora solo funciona con solo 380 operarios. Sin embargo, el Estado animó la migración laboral hacia los países del golfo árabe, quienes luego hacían transferencias financieras a sus familias ${ }^{26}$ mediante el envío de remesas, al punto de que en un excelente estudio, Paul Tabar, aseguraba que el $88 \%$ de los ahorros financieros de las familias en el Líbano proceden de estas transferencias de sus miembros que viven y trabajan fuera del país. Además, esas remesas ayudan a las familias a vivir en un país que tiene pocos servicios sociales ${ }^{27}$.

No obstante, el Estado ha adoptado en su sector público una forma de empleo basado en contratos temporales, con salarios bajos, como en el caso de la compañía libanesa de electricidad (precarización del salario). Así mismo, en esos contratos no se contempla derecho a seguro médico ni a fondos de jubilación, lo que podemos calificar de violencia clasista del Estado, que se hizo acompañar de una estrategia para paralizar la actividad de la central sindical y en su lugar, promover la fragmentación del sindicalismo libanés.

21 Samir Amine, The Relationship between the capitalist History and the Arab Ideology, Beirut, Dar Al Hadatha 1983, 64.

22 Farah Kobieseh, “Workers without unions and unions without workers”, The Permanent Revolution No.6, $2016,26$.

23 Fue el redactor principal de la Constitución del Líbano y autor del famoso dicho: "Líbano: la Suiza del Medio Oriente".

24 Fawaz Traboulsi, Michel Chiha and the Lebanese Ideology. Beirut, Riad Al Rayes Books, 1999, 62 -140.

25 Michel Chiha, Propos de Economie Libanaise, Beirut, Dar al Nahar 1965, 214.

26 Fawwaz Traboulsi," Social Classes and Political Power in Lebanon”, Berlin/ Heinrich Böll Stiftung, $2014,7$.

27 Paul Tabar, Lebanon: A Country of Emigration and Immigration, Beirut, LAU Press 2010, 17. 
Así las cosas, y con ese fin, el gobierno de Hariri legalizó 600 gremios adicionales y además, consiguió infiltrar la cúpula de la central sindical con elementos al servicio del capital y el Estado. Estos elementos consiguieron ganar las elecciones del comité general de la central sindical y con esa estrategia paralizaron su actividad, al punto de que actualmente los trabajadores solo controlan el $7 \%$ de ella. También se convirtió en un arma para explotar a los trabajadores extranjeros del país, que eran el $20 \%$ de toda la fuerza de trabajo del Líbano y con ello consiguieron distraer a los trabajadores locales del problema principal, el de la opresión neoliberal28.

Ya hemos señalado que la caída de la URSS tuvo su efecto catastrófico para los partidos comunistas y movimientos de izquierda en el mundo. Por ejemplo, el partido "Movimiento de la Acción Comunista del Líbano" abandonó su actividad política y el líder del "Partido Socialista Progresista del Líbano", Walid Joumblat, dejó el partido y entró a formar parte del gobierno, sumándose a la élite burguesa, ostentando la representación de la comunidad religiosa "Drusa".

Luego de esto, Joumblat convirtió al partido socialista en una fuerza de derecha ${ }^{29}$ y el partido comunista entró en una crisis estructural y doctrinal insuperable, que en el sentido político y financiero quebró de un modo abrupto sin la guía y las finanzas de Moscú, no pocos de sus miembros desertaron y se afiliaron al "Movimiento del Futuro" el partido político de Rafiq Hariri, el cual ofreció altos salarios a cualquier desertor comunista que se pasaba a sus filas. De esa manera, la derecha "compró" a muchos oportunistas procedentes del partido comunista, a quienes les hicieron atacar al partido en los medios de comunicación. Entonces, el desvió de algunos líderes y organizadores del partido disminuyó la moral de la base del partido.

Paralelo a lo anterior, a principios de 1991, las élites burguesas elaboraron leyes electorales que les eran propicias, basadas en el trabajo con círculos electorales pequeños, ya que los partidos de derecha tenían mayor concentración en los círculos pequeños de las provincias y por otro lado, los partidos de izquierda no tenían ninguna concentración provincial, pero en su lugar, tenían a sus miembros dispersos por todo del país. Entonces los partidos de izquierda perdieron el acceso al el parlamento y las instituciones del país fueron repartidas entre los grupos sectarios y sus élites, y por supuesto, el partido comunista, como partido secular, no tenía ningún acceso al parlamento por la cuota del Estado ${ }^{30}$.

Esta situación obligó a muchos de sus miembros a dejar el partido y buscar oportunidades de empleo en los partidos de derecha. Así, la clase burguesa usó el poder del dinero y las instituciones del Estado para manipular a los miembros de los partidos de izquierda. Además, el objetivo final de la derecha era el aislamiento de los partidos de izquierda y la destrucción de la moralidad del Partido Comunista del Líbano se consiguió con creces.

La paralización del Partido Comunista ha creado otra crisis estructural entre sus líderes y su base, una crisis también entre la teoría y la práctica, lo que le impidió dar apoyo a los movimientos sociales en la época de 1990 y 2000. Además, el partido se autocritico por sus desatinos de la época de la guerra civil y de su programa en la época posterior a 1991. Pero esta crítica no era suficiente y solo tocaba algunos puntos teóricos casi intrascendentes como la denuncia de la promoción del ateísmo en una sociedad marcadamente religiosa y sobre su

28 Mohamad Zbeeb, A Nation Living Day to Day, Alakhbar English. 31/5/2012. http://english.alakhbar.com/node/7917.

${ }^{29}$ Fawwaz Traboulsi, Social Classes and Political Power in Lebanon, Berlin, Heinrich Böll Stiftung, 2014, 41.

30 Imad Salamey \& Rhys Payne, "Parliamentary Consociationalism in Lebanon, Equal Citizenry vs. Quotated Confessionalism", Journal of Legislative Studies, Vol. 14, No. 4, 2008, 463. 
desacuerdo con la dictadura del proletariado en su sentido soviético ${ }^{31}$, lo que no tenía ya ninguna importancia.

Desde ese punto, se impone decir que la teoría sola puede existir en absoluta orfandad si no encuentra una profunda relación con la lucha de clases y la práctica revolucionaria. Marx dijo que la liberación del proletariado es el acto de su propia lucha. Sin dudas, eso no significa que la victoria del proletariado puede ser espontánea. Es necesario preparar, organizar y movilizar a la clase obrera frente a sus enemigos burgueses. Asimismo, es la tarea histórica del partido de la clase trabajadora como vanguardia de los intereses de la clase obrera, porque la dura explotación del capitalismo puede dejar a los obreros sin la brújula necesaria. De ahí que también el partido tiene la tarea de convertir la rebelión espontánea en un movimiento maduro con conocimiento político-económico y revolucionario ${ }^{32}$ y esto le ha faltado a los comunistas libaneses.

Si observamos la mayoría de las declaraciones públicas del Partido Comunista del Líbano en fecha posterior a 1991, encontramos que no existe ningún plan de acción maduro parecido al plan de acción del "Movimiento Nacional" durante la guerra civil. Además, encontramos que en el seno del partido había muchas voces coincidentes con la derecha, haciendo llamados de carácter reformista para hacer cambios cosméticos en la estructura del Estado.

La actividad del partido estuvo limitada a la participación en algunas marchas y celebraciones los 1ro de mayo y para conmemorar la derrota de Israel en su incursión contra Beirut en 1982. Esa crisis entre la teoría y la práctica explica muy bien el nacimiento de los movimientos espontáneos contra el sistema ${ }^{33}$.

\section{¿La muerte de la clase obrero o su resurgimiento?}

Al inicio del año 1996, la clase obrera y la izquierda todavía estaban paralizadas y la derecha comenzó una nueva ofensiva privatizadora. Hariri eliminó los impuestos de aduana para estimular las inversiones extranjeras e impulsar la cultura del consumismo. Por otro lado, para eliminar las pérdidas financieras por no cobrar aranceles, el gobierno implementó unos tipos de impuestos directos dirigidos al pueblo y es importante decir, que aunque se excluyó del pago del gravamen a sectores como los de la educación y la salud, pero también quedaron exentos de pago las actividades de joyería, los casinos y los yates ${ }^{34}$.

Sin dudas el gobierno no quería grabar el lujo de la clase burguesa, pero si quería explotar a los pobres con sus nuevas directivas tributarias, y a pesar de esto, pretendió relanzar de manera renovada su viejo mito: "en el Líbano no existen clases sociales, solo existen grupos religiosos", y en ese escenario, la derecha promovió su nuevo mito: el de "la muerte de la clase obrera en el Líbano". En una entrevista televisada, el presidente Elías El Herrawi dijo: “...No entiendo dónde está la pobreza en mi país, todos los restaurantes están llenos de gente...” y

\footnotetext{
31 Mohamad Najeeb Jamal, “La Crisis del Partido Comunista del Líbano”, Alakhbar 22/03/2015 http://www.alakhbar.com/node/228882

32 Alicia Ermakova y Vólkov Ratnikova, ¿Qué son las clases y la lucha de clases?, Moscú, Editorial Progreso, 1986, 138149.

33 Basem Cheet, The Lebanese Communist Party and the Revolutionary Practice, Communist, socialist and leftist research, 2010, www.ahewar.org/s.asp?aid=231774\&r=0

34 Nisreen Salti \& Jad Shaaban, The Poverty and Equity Implications of a Raise in the Value Added Tax, Microecnomic simulation for Lebanon, Beirut, American University of Beirut 2010, 16.
} 
continuaba diciendo el mandatario: “...el porciento de pobreza en el Líbano está entre el 4\% o $5 \%$..."35. Sin embargo, la dura realidad es bien distinta y parece coincidir con las estadísticas publicadas por el sistema de la ONU que indicaron, que el 28\% de la población en el Líbano vive en la pobreza (menos de 4 dólares cada día) y el $8 \%$ de la población vive en la pobreza extrema (menos de 1.4 dólares en el día) ${ }^{36}$, aunque el presidente El Herrawi viva ajeno a esta realidad.

Y es que en los últimos 27 años las élites del país fallaron en el manejo del Estado. Aparte de la situación económica miserable del pueblo, las élites introdujeron la corrupción en las instituciones del Estado y además, demostraron que son más fieles a sus socios extranjeros que a su pueblo y que son manejadas por las fuerzas políticas regionales e internacionales.

El período 2010-2011 estuvo lleno de marchas estudiantiles contra las altas tarifas de la educación privada y la situación precaria de la única universidad pública del país. En abril de 2011, miles de jóvenes universitarios, intelectuales y obreros marcharon con la bandera del cambio del régimen corrupto de las élites y demandaron la secularización del país. La derecha respondió infiltrando las marchas con sus miembros para crear conflictos y provocar la represión policial. Finalmente, el movimiento fue palideciendo hasta esfumarse y todo esto, debido a que las marchas fueron espontáneas, sin organización y terminaron reprimidas por el Estado.

De tal manera, la irrupción del estudiantado en las calles de Beirut tomó por sorpresa a la élite burguesa en el poder y al mismo tiempo, le obligaron a despojarse de su máscara de democracia, llegando incluso en 2014 a posponer las elecciones generales ${ }^{37}$, ya en 2013 habían anunciado la posposición de las elecciones parlamentarias por razones de seguridad 38 .

A su vez, el despertar de la clase obrera continúa desarrollándose de una manera espontánea, en el año 2012 los trabajadores de la compañía libanesa de la electricidad ocuparon por 94 días una de las mayores plantas de la empresa, en la que se considera la rebelión más larga en la historia moderna del Líbano. Posterior a ello y en un acto típico de la derecha libanesa, un partido con la bandera chiita, declaró que el partido estaba de acuerdo con la rebelión para mejorar la situación de los trabajadores musulmanes, pero por otro lado, otro partido de derecha, pero que reclama su filiación con las derechas de los cristianos, indicó que el partido estaba contra la rebelión, porque mediante esta los musulmanes lo que pretendían era controlar la compañía 39 .

Este es un ejemplo muy sencillo de cómo la derecha articula su propaganda en torno a la cuestión religiosa y trata de ocultar la existencia de una compleja estructura socio clasista al interior de la sociedad libanesa, preñada de importantes contradicciones, que trasciende la estructura confesional del país, con el objetivo de encubrir la realidad y crear desavenencias entre los trabajadores musulmanes y cristianos para conjurar la lucha de clases y fortalecer los mecanismos de dominación capitalista.

La sublevación de los eléctricos había sido una clarinada que encendió las alarmas entre la burguesía, por 94 días los trabajadores consiguieron mantenerse firmes a partir de conseguir

\footnotetext{
35 Fawwaz Traboulsi, Social Classes and Political Power in Lebanon, Berlin, Heinrich Böll Stiftung, 2014,71.

36 UNDP “Millennium Development Goals Lebanon" Report 2008, 11.

37 Antoine Apprioual, Lebanon's Political Stalemate: The Failure of the Sectarian Regime, Pomeas Policy Brief No.11, FEBRUARY 2016, 5.

38 Kameel Dagher, "The rough birth of the Lebanese Revolution, but it is possible!", The permanent revolution, No.6 December, 2016, 19

39 Maysa Sheed: Baseel, will not cover the electricity workers and the mafia behind them, 30/05/2012 http://bit.ly/2g7UWIP
} 
la unidad y demandaron seguro médico y contratos más justos. Después de esto, terminaron su rebelión y entonces fueron manipulados en las negociones con el Estado y la compañía y perdieron la puja. Además, se hizo evidente la falta de cohesión social en el país, ya que esta batalla coincidió con el período de marchas y protestas de los estudiantes y profesores de Beirut, pero estos nunca apoyaron la rebelión en la planta de electricidad.

Asimismo, tanto el partido comunista como el resto de los movimientos de izquierda apoyaron la rebelión popular solo en sus discursos, pero no hicieron nada más, al punto de que uno de los líderes de la rebelión en la planta eléctrica llegó a decir: “...Fuimos abandonados por el pueblo del Líbano, luchamos solos por 94 días con poca comida (...) nos sentimos abandonados y nuestro espíritu decayó por eso...". Ante esta realidad, algunos activistas, portadores de un pensamiento revolucionario consciente, comenzaron a movilizarse en el marco de nuevos movimientos sociales diferentes de sus partidos y sindicatos tradicionales, un fenómeno que se ha hecho presente también en América Latina y en otras latitudes.

Al interior del propio Partido Comunista del Líbano comenzaron a levantarse voces procedentes de un segmento de los jóvenes intelectuales de esa militancia, quienes se pronunciaron por cambiar la actitud claudicante del partido. En esa misma época, los profesores y maestros formaron el "Comité de Coordinación de Gremios", como un movimiento paralelo a la "Unión General de los Trabajadores" y miles de ellos ocuparon las calles de la capital para demandar mejor salario y condiciones para el desarrollo del proceso docente educativo, pero el Estado respondió con una clara negativa, arguyendo de que no había ninguna fuente para financiar estas demandas.

El jefe del Comité, Hanna Gharib, presentó en público una investigación que develaba una posible fuente para obtener los recursos con los cuales financiar las demandas de los docentes a partir de imponer gravámenes a los propietarios de hoteles, casinos, yates, es decir, obligando a la clase burguesa a financiar el futuro del país ${ }^{40}$. Este hecho le granjeó una creciente autoridad a Hanna Gharib, un profesor y luchador social quien, sorpresivamente, fue electo en 2015 como secretario general del partido comunista. A esta elección se le atribuye el cambio de actitud en el seno del partido y se asume como parte del ascenso de los jóvenes e intelectuales comunistas, que no estaban de acuerdo con la actitud del partido, a la cúpula partidista.

En ese escenario de cambios, en el verano de 2015 estalló la "crisis famosa de la basura" en el Líbano, que comenzó después de que la compañía privada "Sueclean”, responsable por la recolección de los desechos sólidos en el país, suspendió de manera unilateral su contrato con el gobierno y dejar de realizar su actividad. Como resultado de esto, las calles del país se llenaron de basura que se iba acumulando día a día, lo que representaba un claro peligro para la salud de la población. El Estado no reaccionó de manera debida y demoró, de manera injustificada e innecesaria, la firma de un nuevo contrato con otra compañía.

Miles de libaneses se convencieron entonces de que el Estado burgués y las élites nacionales solo velaban por sus propios intereses y no les importaban las necesidades del pueblo, de ahí que este fuera el detonante que llevó a que se produjeran masivas manifestaciones en todo el país, muy fuerte en la capital, donde los pobladores ocuparon el centro de Beirut y demandaron al gobierno por una solución para la crisis.

En tanto, la gente llana comenzó a organizarse para enfrentar al gobierno, activistas de movimientos ecologistas y de las organizaciones no gubernamentales, formaron el movimiento

40 Rajana Hamyeh, Hanna Gharib the Union Chief Goes Back to School, Alakhbar 2013 http://english.alakhbar.com/node/15195. 
de orientación ambientalista "You Stink", además, activistas de tendencias izquierdistas formaron el movimiento contestatario "Badna Nhaseb" y la movilización alcanzó niveles significativos, como no había precedentes en la historia del Líbano, por lo que el Estado decidió terminar las marchas mediante el uso de la fuerza y la violencia, luego de lo cual, el movimiento perdió todo su impulso y la cantidad de marchas se ha hecho mínima, lo mismo que sus participantes, que desde algunas donde participaron miles de personas hasta llegar a unos pocos cientos en la actualidad 41 .

Sin duda, el auge de rebeliones y marchas, y los cambios estructurales en el partido comunista, crearon alguna esperanza de estar en presencia del inicio de un proceso de cambios revolucionarios, sobre todo porque los mitos de la clase burguesa quedaron en entredicho y se demostró, que en el Líbano la clase obrera no estaba muerta y que entre los grupos religiosos no existían contradicciones de las llamadas fundamentales, también había salido a relucir el nivel de pobreza existente en el Líbano y con ello, las disfuncionalidades del régimen de la democracia consociacional de las élites en el país de los cedros. En tanto, se trató de justificar entonces los problemas por los que atravesaba el Líbano alegando que eran resultado del efecto geopolítico ${ }^{42}$ de la crisis permanente del Oriente Medio.

Pero la verdad es que, aunque la situación regional influye, en el país se están operando importantes cambios, aunque se impone reconocer que la sociedad no está completamente madura para oponerse al statu quo y eso es lo que explica que las movilizaciones sean perecederas y no consigan sus objetivos, además de que en todos los casos pierden el impulso muy rápido. Las causas de esto se pueden resumir en los siguientes puntos:

- La ausencia de la teoría y la visión política: El surgimiento de dichos movimientos han sido de naturaleza espontánea en respuesta a hechos concretos del accionar de los mecanismos de dominación capitalista, lo que demuestra que sus acciones no trascienden el nivel de la psicología política en sus participantes. Por ejemplo, la crisis de la basura que tuvo un detonante técnico-ambiental o lo de las demandas por un mejor salario, cuando en realidad es necesario cambiar el sistema político del país, desmontar el orden neoliberal, responsable del auge de la miseria de las masas, para lo cual es necesario desarrollar profundos conocimientos y una adecuada cultura política clasista, que encuentre cauce en una estrategia de lucha para un cambio revolucionario.

- La localización de las protestas: Los movimientos espontáneos de protesta fallaron, como se vio durante la crisis de la basura, porque las marchas se desarrollaron solo en la capital del país y no trascendieron al interior del país, que se mantuvo ajeno a esta problemática.

- La ausencia de organización y líderes: La mayoría de las marchas y manifestaciones fueron promovidas en las redes sociales y su convocatoria era frágil, no hubo líderes que se hicieran responsables de la lucha y su conducción, reprimirlas fue muy fácil.

- La ausencia de coordinación entre los activistas, militantes y trabajadores: Nunca se pudo superar el sectarismo, por ejemplo, los ambientalistas nunca apoyaron la

\footnotetext{
${ }^{41}$ Lena Herzog, "Nothing but a demonstration? The civil society movement during the garbage crisis in Beirut after July 2015”, Heinrich Böll Stiftung Middle East 2016, 4

42 Kareem Chehayeb, One year after Lebanon's \#YouStink movement: popular uprising imminent, The New Arab 30 Agosto 2016

https://www.alaraby.co.uk/english/comment/2016/8/30/one-year-after-lebanons-youstink-movement-popularuprising-imminent.
} 
rebelión de la compañía de electricidad, ni los profesores y maestros apoyaron al movimiento de los ambientalistas. La falta de unidad y coordinación entre todos los que sufren del capitalismo y tratan de enfrentarlo los hace muy débiles frente a los embates de la derecha.

- La barrera ideológica: Un grave problema en el Líbano, como mismo ocurre en América Latina, es la existencia de supuestas, pero infranqueables barreras ideológicas, que afectan principalmente a las fuerzas de izquierda. En el escenario libanés, los militantes ambientalistas o democráticos rechazaron la coordinación con los militantes de pensamiento Marxista, en tanto, la derecha operó como una unidad sólida e inquebrantable en defensa de sus intereses de clase y utilizó con acierto la propaganda política, ensanchando las brechas entre sus oponentes, como cuando propagaron la idea de que los comunistas querían supeditar las marchas de protesta a su favor para tratar de renovar su gloria, que aseguraban, había muerto con la Unión Soviética ${ }^{43}$.

\section{¿Qué hacer? Una visión por el futuro}

En el aniversario cien de la revolución de octubre de 1917, sería bueno recordar las tácticas empleadas por los bolcheviques en la época de la revolución burguesa. Lenin, en su tesis “¿Qué hacer?” señalaba: “...es necesario saber el carácter y el contenido principal de nuestra agitación política, nuestras tareas de organización y el plan de acción a llevar adelante por la revolución..." 44 . En ese sentido, el Partido Comunista del Líbano tiene la tarea de superar su propia crisis existencial causada por la caída de la URSS, a cuyo partido estaba supeditado y crear su propio plan de lucha revolucionaria para todo el Líbano.

No es aceptable seguir hablando, en el año 2017, sobre la falta de apoyo financiero de la URSS o continuar viviendo de supuestas glorias ancladas en la memoria histórica de cuando la lucha armada durante la guerra civil, que tampoco coronaron con el éxito.

Así, el modelo de reconfiguración revolucionaria, presente en algunos movimientos políticos y sociales de América Latina, puede ofrecer un buen ejemplo de cómo avanzar en un proyecto revolucionario sin la presencia de la URSS. El partido necesita construir una nueva confianza entre sus miembros, si la derecha compró algunos oportunistas, el partido tiene que formar a sus nuevos líderes fieles a la causa nacional y de sus trabajadores.

Es necesario también educar y organizar a la clase trabajadora libanesa para impulsar la revolución y avanzar hasta conseguir la verdadera victoria45, para ello, en 2016, el nuevo comité central del partido abrió una escuela para la enseñanza del marxismo en sus oficinas centrales en Beirut con el propósito de educar a las masas y a su militancia en los principios del materialismo dialéctico, la economía política y el estudio sobre el desarrollo del capitalismo en el Líbano 46 .

No obstante, el partido necesita entender a los otros movimientos de izquierda que nacieron en una época donde el partido quedó paralizado y establecer una buena coordinación

\footnotetext{
43 Atallah al Salim, Why did the recent movement of activism fail in Lebanon? A critique of an activist, 4/02/2016

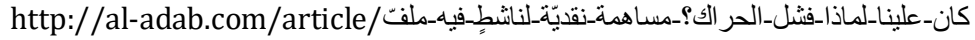

44 Vladimir Lenin, “Obras Escogidas en Doce Tomos, ¿Qué hacer? tomo 2", Moscú / Editorial Progreso 1975,2

45 Vladimir Lenin, "Obras Escogidas en Doce Tomos, Dos tácticas de La Social Democracia en La Revolución Democrática, Tomo 3", Moscú /Editorial Progreso 1975, 3-7

46 El Partido Comunista del Libano Sito Oficial Agosto 2016

http://www.lcparty.org/index.php?option=com content\&id=10378:2016-08-30-13-16-48
} 
con ellos. Es necesario que todos los movimientos de izquierda formen un frente unido con un plan de lucha y una organización que les permita estar presentes en todas las batallas de los obreros frente de la derecha explotadora.

En este nuevo escenario se impone seguir las enseñanzas de Lenin cuando aseguró: “...la lucha no se logra solo con eslóganes sino también con acciones..."47. Además, es imprescindible llegar a los obreros del campo y de las provincias y no solo concentrar su actividad en la capital. Si la derecha le cerró todas las posibilidades para la participación en el parlamento, es necesario luchar fuera de las instituciones del Estado y dejar el sueño de algunos oportunistas de entrar a su aparato como coyunda incoherente, y mientras eso no cambie, tendremos que reconocer de que a la clase obrera en el Líbano le falta la vanguardia política que no puede encontrar ni en el partido comunista, ni en las organizaciones de izquierda y que una situación así no se había vivido en ningún momento de su historia moderna.

\section{Conclusiones}

El sistema de mecanismos de dominación clasista impuesto por la élite burguesa a las masas trabajadoras en el Líbano entró en una considerable crisis interna, incluso, antes del estallido de la guerra civil de 1975 y puso al descubierto de que esta élite no fue capaz de superar el cambio de paradigma que introdujo la revolución de las tecnologías.

La dependencia política y económica de la burguesía libanesa de los círculos del imperialismo internacional la llevó a elevar los niveles de explotación sobre la sociedad libanesa y a incrementar el índice de injusticia, donde las compañías extranjeras consiguieron prebendas desorbitantes de la burguesía nacional para explotar a los trabajadores del país.

Aunque la propaganda oficial se esfuerce en negarlo, el incremento de los índices de explotación, reveló la profunda división clasista existente en la sociedad libanesa, lo que dio lugar a la aparición de sindicatos inter sectarios y de departidos políticos de izquierda que se enfocaron en los problemas de desigualdad social donde encontraron espacio cristianos, musulmanes, judíos y miembros de otras entidades confesionales. Sin embargo, la élite gobernante hizo frente a los movimientos políticos y sindicales inter sectarios, mediante la difusión de una propaganda malsana, basada en el sectarismo y en busca de exacerbar las diferencias étnicas y religiosas e ignorar y encubrir las diferencias de clase.

En un intento por ocultar la existencia de la lucha de clases, y hasta de las clases mismas, la élite imperante vinculó los asuntos de la desigualdad social con el desequilibrio demográfico sectario, que señaló era causado por el flujo de los refugiados palestinos y la crisis geopolítica regional y global y después de la guerra civil, la derecha comenzó un nuevo plan neoliberal para destruir la izquierda y sus organizaciones, operando más rápido que la clase trabajadora y retomando hegemónicamente los nuevos espacios de poder que surgían en la contemporaneidad y llevando adelante una propaganda inescrupulosa con la que ha conseguido reforzar la cultura dominante sobre la cultura de los dominados.

La derecha libanesa en la época neoliberal, mediante el poder del dinero y la publicidad política, consiguió paralizar a la "Unión del Trabajo, al "Partido Comunista del Líbano", y a la izquierda toda. Además, usó la propaganda racista y religiosa para crear exacerbar los desacuerdos y las contradicciones entre la clase trabajadora libanesa, consiguiendo imponer su agenda y reforzar los mecanismos de dominación de clase sobre clase.

47 Karim Mroweh, For a New Rise of the Left in the Arab World, Beirut, Dar Al Saaki , 2010, 71 
Finalmente, y sin otras opciones cosméticas con las que manipular a las masas, la derecha ha comenzado a manifestarse de una manera más violenta, con lo que llevaron al país a una parálisis política y económica, con lo que han provocado un lento, pero creciente auge del movimiento obrero, quienes tienen ante sí muchas tareas históricas que resolver. Además, la izquierda revolucionaria del Líbano tiene la responsabilidad de tomar su destino y el del país en sus propias manos y trabajar por la victoria final de la nación a través de la lucha de su clase trabajadora.

\section{Bibliografía}

\section{Libros}

- Alica Ermakova y Vólkov Ratnikova, ¿Qué son las clases y la lucha de clases?, Moscú, Editorial Progreso, 1986.

- Amel, Mahdi, In the Secterian State, Beirut, Dar Al Farabi, 1986.

- Amel Mahdi, Introductions to Critic the Sectarian Thought, Beirut, Dar Al Farabi, 1989. Fawwaz Traboulsi, Social Classes and Political Power in Lebanon, Berlin, Heinrich Böll Stiftung, 2014.

- Fawaz Traboulsi, A History of Modern Lebanon From the Imarah to the Taef Accords, Beirut, Riyad Al Rayes Books, 2008.

- Fawaz Traboulsi, Michel Chiha and the Lebanese Ideology, Beirut, Riad Al Rayes Books, 1999.

- $\quad$ Karim Mroweh, For a New Rise of the Left in the Arab World, Beirut, Dar Al Saaki, 2010. Michel Chiha, Propos de Economie Libanaise, Beirut, Dar al Nahar 1965.

- Nisreen Salti \& Jad Shaaban, "The Poverty and Equity Implications of a Raise in the Value Added Tax, Microecnomic simulation for Lebanon", Beirut / American University of Beirut 2010.

- Paul Tabar, Lebanon: A Country of Emigration and Immigration, Beirut, LAU Press 2010.

- Reinaldo Sanchez Porro, El Libano Crisis y Comunidades Confesionales (1840-1943), La Habana, Editorial Félix Varela, 2001

- Samir Amine, The Relationship between the capitalist History and the Arab Ideology, Beirut, Dar Al Hadatha 1983.

- Sulieman Takieldeen, The Historical Development of the Lebanese Crisis 1920-1970, Beirut, Dar Ibn Khaldoun, 1977.

- Suleiman Takieldeen, El Tema del sectarismo en el Líbano, sus raíces y Desarrollo, Beirut, Dar Ibin Khaldoun, 1980.

- Vladimir Lenin, “Obras Escogidas en Doce Tomos, ¿Qué hacer? tomo 2”, Moscú / Editorial Progreso 1975.

- Lenin Vladimir, "Obras Escogidas en Doce Tomos, Dos tácticas de La Social Democracia Revistas en La Revolución Democrática, Tomo 3", Moscú /Editorial Progreso 1975.

- Farah Kobieseh, "Workers without unions and unions without workers", The Permanent Revolution No.6 2016, 24-39.

- Kameel Dagher: "The rough birth of the Lebanese revolution, but it is possible!" The permanent revolution, No.6 december, 2016, 13-23. 
- Lena Herzog, "Nothing but a demonstration? The civil society movement during the garbage crisis in Beirut after July 2015", Heinrich Böll Stiftung Middle East 2016, 3-10.

- Imad Salamey \& Rhys Payne, "Parliamentary Consociationalism in Lebanon, Equal Citizenry vs. Quotated Confessionalism", Journal of Legislative Studies, Vol. 14, No. 4, 2008, 451-473.

- Hamade Sultan, "Líbano: ¿Crisis de las Comunidades Confesionales o Crisis del Sistema Burgués?”, Marxismo y Revolución No.2 Febrero, 2018, Pp. 1-10.

- Villar Barroso, Oscar Julián: "Los fulgores de Octubre en las estepas centroasiáticas". Revista Universidad de La Habana, no.284. La Habana. jul.-dic. 2017. ISSN: 0253-9276.

Publicaciones periódicas

- Kareem Chehayeb, One year after Lebanon's \#YouStink movement: popular uprising imminent, The New Arab $30 \quad$ Agosto 2016 https://www.alaraby.co.uk/english/comment/2016/8/30/one-year-after-lebanonsyoustink-movement-popular-uprising-imminent

- Mohamad Zbeeb, a Nation Living Day to Day. Alakhbar English. 31/5/2012. http://english.al-akhbar.com/node/7917

- Maysa Sheed: Baseel, will not cover the electricity workers and the mafia behind them 30/05/2012 http://bit.ly/2g7UWIP

- Najeeb Jamal, La Crisis del Partido Comunista del Libano, Alakhbar 22/03/2015 http://www.al-akhbar.com/node/228882

\section{Reportajes}

- Rajana Hamyeh, Hanna Gharib The Union Chief Goes Back to School, Alakhbar 2013 http://english.al-akhbar.com/node/15195

- Antoine Apprioual, Lebanon's Political Stalemate: The Failure of the Sectarian Regime,

- Elizabeth Picard, The Arab Uprisings and Social Rights: Asian Migrant Workers in Lebanon, Paris / Institut de Recherches et d'Études sur le Monde Arabe et Musulman Centre National de la Recherche Scientifique, 2014.

- Pomeas Policy Brief No.11, February 2016 http://ipc.sabanciuniv.edu/wpcontent/uploads/2016/02/pomeas brief.pdf

- Samir Makdisi and Richard Sadaka, The Lebanese Civil War, 1975-1991, Lecture and Working Paper Series No.3 / American University of Beirut Institute of Financial Economics 2003.

- UNDP, Millennium Development Goals Lebanon, Report 2008. https://www.unescwa.org/sites/www.unescwa.org/files/u593/lebanon 2008 en.pdf

- USADOS, Annual Labour report 1972-1973, Beirut, 1973.

\section{Fuentes electrónicas}

- Atallah al Salim, Why did the recent movement of activism fail in Lebanon? A critique of

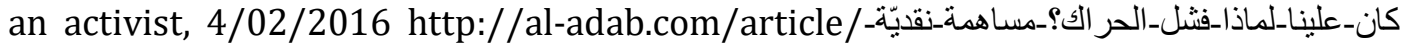
لناشطِفيه-ملفة

- El Partido Comunista del Libano Sito Oficial Agosto 2016 http://www.lcparty.org/index.php?option=com content\&id=10378:2016-08-30-13$\underline{16-48}$

- Basem Cheet, The Lebanese Communist Party and the Revolutionary Practice, Communist, socialist and leftist research, 2010, www.ahewar.org/s.asp?aid $=231774 \& \mathrm{r}=0$ 